\title{
Physician Factors Associated with Inappropriate Vitamin B12 Prescribing in Ontario, Canada
}

J Gen Intern Med 36(9):2888-90

DOI: $10.1007 / \mathrm{s} 11606-020-06185-3$

(C) Society of General Internal Medicine 2020

\section{INTRODUCTION}

Nearly two-thirds of Ontarians over the age of 65 are prescribed parenteral vitamin B12 without biochemical evidence of B12 deficiency in the year preceding their first prescription, costing an estimated $\$ 46$ million CAD. ${ }^{1}$ To our knowledge, there is no published literature characterizing physician factors associated with inappropriate B12 prescribing. We assessed this using population-based databases.

\section{METHODS}

We undertook a retrospective cohort study using health system administrative databases available within ICES, in Ontario, Canada. Data sets were linked using unique, encoded identifiers and analyzed at ICES. All persons 65 years or older who received at least 1 intramuscular B12 prescription from January 1, 2011, to September 30, 2015, were included. Data were analyzed from July 26, 2018, to November 22, 2018. The primary outcome was inappropriate B12 supplementation, identified when persons with either a normal serum B12 level ( $>221 \mathrm{pmol} / \mathrm{L}$, consistent with the National Health and $\mathrm{Nu}-$ tritional Examination Survey upper limit of normal for marginal B12 deficiency) ${ }^{2}$ or without a documented B12 level in the 12 months prior, received their first intramuscular B12 prescription. We performed univariate and multivariable analyses using multilevel logistic regressions (adjusting for clustering within prescribing physician groups) to identify physician factors associated with inappropriate prescribing of vitamin B12. Physician factors included age, sex, years in practice, prescription volume, specialty, and medical school location (Canadian versus International). Patient variables included in the multivariable analysis were age, gender, rurality, income status, and comorbidities (Table 1). The use of data for this project is authorised under Section 45 of Ontario's Personal Health Information Protection Act.

Dr. Yulia Lin and Dr. Matthew C Cheung contributed equally as co-senior authors to this study.

Received June 2, 2020

Accepted August 24, 2020

Published online September 9, 2020
RESULTS

A total of 12,978 physicians prescribed 405,469 intramuscular B12 prescriptions to 146,850 persons, of which 93,615 were deemed inappropriate (Table 1). ${ }^{1}$ Physician factors (Table 2) associated with inappropriate B12 supplementation included higher volume of parenteral B12 prescribing (multivariable OR, 1.03 per 10 additional patients prescribed $\mathrm{B} 12 ; 95 \% \mathrm{CI}$, 1.02-1.05), or having practiced for more years (OR, 1.15; 95\% CI, 1.12-1.18). Female physicians were less likely (OR, 0.87; 95\% CI, 0.81-0.93) to prescribe intramuscular B12 inappropriately compared with their male counterparts. When compared with primary care providers, internal medicine subspecialists were more likely to prescribe B12 inappropriately (OR $1.24 ; 95 \%$ CI 1.01-1.54), whereas geriatricians were less likely (OR, 0.35 ; 95\% CI, 0.24-0.52). International medical graduates (OR, 0.83; 95\% CI, 0.77-0.89) were less likely to prescribe parenteral B12 inappropriately when compared with Canadian medical graduates.

\section{DISCUSSION}

We identified numerous physician factors associated with inappropriate prescribing of B12. Physicians in practice for more years were more likely to prescribe inappropriately, consistent with previous Canadian studies, which may reflect the impact of pharmacologic training previously provided in medical school. ${ }^{3}$ Female physicians were more likely to prescribe B12 appropriately; this contributes to a growing literature demonstrating that women are more likely to adhere to clinical guidelines and may provide higherquality care. ${ }^{4}$ It has been reported that geriatricians are more aware of the evidence supporting B12 supplementation, compared with general practitioners ${ }^{5}$; consistent with our observation, they were more likely than primary care providers to prescribe B12 appropriately. Finally, B12 deficiency is more common in low- and middle-income countries. ${ }^{2}$ As such, increased physician familiarity with B12 prescribing in these countries could explain why international medical graduates prescribed B12 more appropriately than their Canadian counterparts.

Our limitations include not being able to understand why particular physician groups were associated with overprescribing vitamin B12, or why B12 was prescribed without evidence of deficiency. Other limitations include using an abridged lookback period, which might have 
Table 1 Characteristics of Patients who Received Intramuscular

B12, and of Physicians who Prescribed an Intramuscular B12 Injection from January 1, 2011, to September 30, 2015

\begin{tabular}{|c|c|c|}
\hline \multicolumn{3}{|l|}{ Patient characteristics } \\
\hline \multicolumn{3}{|l|}{ Age } \\
\hline Mean (SD) & $76.5(8.1)$ & \\
\hline Median (IQR) & $76(14.0)$ & \\
\hline Range & $65-110$ & \\
\hline \multicolumn{3}{|l|}{ Age categorized } \\
\hline $65-69$ & 36,866 & 25.1 \\
\hline $70-74$ & 28,196 & 19.2 \\
\hline $75-79$ & 28,014 & 19.1 \\
\hline $80-84$ & 26,055 & 17.7 \\
\hline $85-89$ & 18,384 & 12.5 \\
\hline $90+$ & 9335 & 6.4 \\
\hline \multicolumn{3}{|l|}{ Sex } \\
\hline Female & 86,813 & 59.1 \\
\hline Male & 60,037 & 40.9 \\
\hline \multicolumn{3}{|l|}{ Location of residence } \\
\hline Rural & 12,692 & 8.6 \\
\hline Urban & 124,359 & 84.7 \\
\hline \multicolumn{3}{|l|}{ Neighbourhood income quintile } \\
\hline Q1 (lowest) & 32,905 & 22.4 \\
\hline Q2 & 32,230 & 22.0 \\
\hline Q3 & 29,828 & 20.3 \\
\hline Q4 & 27,679 & 18.9 \\
\hline Q5 (highest) & 23,573 & 16.1 \\
\hline \multicolumn{3}{|l|}{ Co-morbidities } \\
\hline Crohn's disease, ulcerative colitis, and & 9309 & 6.3 \\
\hline \multicolumn{3}{|l|}{ malabsorption } \\
\hline Pernicious anemia & 40,908 & 27.9 \\
\hline Dementia & 14,844 & 10.1 \\
\hline Neuropathy & 2471 & 1.7 \\
\hline \multicolumn{3}{|l|}{ ADG Co-morbidity score } \\
\hline Low & 24,135 & 16.4 \\
\hline Moderate & 51,920 & 35.4 \\
\hline High & 70,795 & 48.2 \\
\hline \multicolumn{3}{|l|}{ Physician characteristics } \\
\hline \multicolumn{3}{|l|}{ Age } \\
\hline \multirow{2}{*}{ Mean (SD) } & \multirow{2}{*}{\multicolumn{2}{|c|}{$\begin{array}{r}51.0 \\
(12.3)\end{array}$}} \\
\hline & & \\
\hline Median (IQR) & \multicolumn{2}{|l|}{$51(18)$} \\
\hline Range & \multicolumn{2}{|l|}{$25-90$} \\
\hline Sex & & \\
\hline Female & 4595 & 40.0 \\
\hline Male & 6840 & 60.0 \\
\hline Type of practice & & \\
\hline Family physician (CCFP, FCFP) & 9924 & 86.0 \\
\hline Emergency medicine (CCFP-EM, FRCPC) & 218 & 1.9 \\
\hline Medicine specialist (FRCPC) & 797 & 6.9 \\
\hline Surgical specialist (FRCSC) & 189 & 1.6 \\
\hline Geriatrics & 70 & 0.6 \\
\hline Other & 348 & 3.0 \\
\hline Location of practice & & \\
\hline Rural & 1120 & 9.8 \\
\hline Urban & 10,321 & 90.2 \\
\hline Years of practice (years since graduation) & & \\
\hline$\leq 5$ years & 669 & 5.9 \\
\hline $5-15$ years & 2252 & 19.7 \\
\hline $15-30$ years & 4363 & 38.2 \\
\hline $30+$ years & 4147 & 36.3 \\
\hline Medical school location & & \\
\hline Canadian Medical Graduate (CMG) & 7763 & 69.5 \\
\hline International Medical Graduate (IMG) & 3411 & 30.5 \\
\hline Number of prescriptions given within the tim & iod & \\
\hline Mean $(\mathrm{SD})$ & $\begin{array}{r}11.8 \\
(20.8)\end{array}$ & \\
\hline Median (IQR) & $5(12)$ & \\
\hline Range & $1-500$ & \\
\hline
\end{tabular}

$S D$, standard deviation; IQR, interquartile range; $C C F P$, Certification in the College of Family Physicians; FCFP, Fellowship in the College of Family Physicians; FRCPC, Fellow of the Royal College of Physicians of Canada; FRCSC, Fellow of the Royal College of Surgeons of Canada; ADG, Johns Hopkins Aggregated Diagnosis Groups (The Johns Hopkins ACG® System)
Table 2 Physician Characteristics Associated with Inappropriate Vitamin B12 Prescribing

\begin{tabular}{|c|c|c|c|c|}
\hline & \multicolumn{4}{|l|}{ OR (95\% CI) } \\
\hline & $\begin{array}{l}\text { Univariate } \\
\text { analysis }\end{array}$ & $p$ & $\begin{array}{l}\text { Final } \\
\text { multivariable }\end{array}$ & $p$ \\
\hline \multicolumn{5}{|l|}{ Physician factors } \\
\hline $\mathrm{Age}^{\mathrm{a}}$ & $1.17(1.14,1.21)$ & $\begin{array}{l}< \\
0.001\end{array}$ & - & - \\
\hline $\begin{array}{l}\text { Physician's } \\
\text { prescription } \\
\text { volume (past } \\
365 \text { days)* a }\end{array}$ & $1.03(1.01,1.05)$ & $\begin{array}{l}< \\
0.001\end{array}$ & $1.03(1.02,1.05)$ & $\begin{array}{l}< \\
0.001\end{array}$ \\
\hline $\begin{array}{l}\text { Years since } \\
\text { graduation* a }\end{array}$ & $1.17(1.14,1.20)$ & $\begin{array}{l}< \\
0.001\end{array}$ & $1.15(1.12,1.18)$ & $\begin{array}{l}< \\
0.001\end{array}$ \\
\hline $\begin{array}{l}\text { Physician's } \\
\text { sex (F vs M)* }\end{array}$ & $0.79(0.74,0.84)$ & $\begin{array}{l}< \\
0.001\end{array}$ & $0.87(0.81,0.93)$ & $\begin{array}{l}< \\
0.001\end{array}$ \\
\hline $\begin{array}{l}\text { Physician's } \\
\text { specialty (REF: } \\
\text { GP/FP) }\end{array}$ & 1.00 & & & \\
\hline $\begin{array}{l}\text { Emergency } \\
\text { medicine }\end{array}$ & $1.04(0.79,1.37)$ & 0.79 & $1.08(0.81,1.42)$ & 0.61 \\
\hline $\begin{array}{l}\text { Medicine } \\
\text { subspecialist* }\end{array}$ & $1.25(1.05,1.48)$ & 0.01 & $1.24(1.01,1.54)$ & 0.04 \\
\hline $\begin{array}{l}\text { Surgical } \\
\text { specialist }\end{array}$ & $1.16(0.86,1.58)$ & 0.33 & $1.30(0.71,2.37)$ & 0.39 \\
\hline Geriatrics* & $0.48(0.36,0.66)$ & $\begin{array}{l}< \\
0.001\end{array}$ & $0.35(0.24,0.52)$ & $\begin{array}{l}< \\
0.001\end{array}$ \\
\hline Other & $1.04(0.82,1.32)$ & 0.75 & $1.07(0.69,1.66)$ & 0.77 \\
\hline $\begin{array}{l}\text { International } \\
\text { vs Canadian } \\
\text { graduate* }\end{array}$ & $0.82(0.77,0.88)$ & $\begin{array}{l}< \\
0.001\end{array}$ & $0.83(0.77,0.89)$ & $\begin{array}{l}< \\
0.001\end{array}$ \\
\hline
\end{tabular}

*Significant under 0.05 level in the final model and the univariate analysis

${ }^{a}$ Odds ratios are presented in increments of 10. Every increase in 10 more patients or 10 more years are associated with the odds ratio presented

${ }^{b}$ Adjusted odds ratios are presented after adjustment of patients' characteristics of age, sex, rurality, anemia, dementia, neuropathy, $A D G$ groups, and income quintile

$C I$, confidence interval; GP/FP, general practice or family practice

misclassified persons undergoing treatment for chronic B12 deficiency as receiving inappropriate supplementation. However, we are reassured that our data were not meaningfully impacted by left censoring as a 24-month lookback revealed similar rates of inappropriate prescribing. ${ }^{6}$ Lastly, while using methylmalonic acid and homocysteine levels to corroborate vitamin B12 deficiency may have strengthened our study, we feel having done so would not have reflected real-world practice given their cost and limited availability ${ }^{2}$; furthermore, they are not included in ICES databases. Future quality improvement initiatives should target the identified physician groups, to reduce this burden of unnecessary care.

Acknowledgments: We thank IMS Brogan Inc. for use of their Drug Information Database.

William K. Silverstein, $M D^{1,2}$

Yulia Lin, MD, FRCPC ${ }^{1,3,4,5}$

Christoffer Dharma, $\mathrm{MSc}^{6}$

Ruth Croxford, $\mathrm{MSc}^{6}$

Matthew C. Cheung, MD, SM, FRCPC $C^{1,3,6}$ 
${ }^{1}$ Department of Medicine, Faculty of Medicine, University of Toronto,

Toronto, ON, Canada

${ }^{2}$ Department of Medicine, Sunnybrook Health Sciences Centre,

Toronto, Ontario, Canada

${ }^{3}$ Division of Medical Oncology \& Hematology, Sunnybrook Health Sciences Centre,

Toronto, ON, Canada

${ }^{4}$ Department of Laboratory Medicine \& Molecular Diagnostics, Sunnybrook Health Sciences Centre, Toronto, ON, Canada

${ }^{5}$ Department of Laboratory Medicine and

Pathobiology, University of Toronto,

Toronto, ON, Canada

${ }^{6}$ ICES,

Toronto, ON, Canada

Corresponding Author: William K. Silverstein, MD; Department of Medicine, Sunnybrook Health Sciences Centre, Toronto, Ontario, Canada (e-mail: William.Silverstein@mail.utoronto.ca).

Authors' Contribution WKS, YL, and MCC devised the study. CD and $R C$ conducted data analysis. Data was reviewed by WKS, YL, $C D, R C$, and MCC. Manuscript was drafted by WKS. Manuscript was revised by YL and MCC. All authors read and approved the final manuscript. YL is a consultant for Pifzer and was on the Advisory Board for Amgen.

Funding This study was supported by research funding from the Sunnybrook Hospital Foundation. This study was also supported by ICES, which is funded by an annual grant from the Ontario Ministry of Health and Long-Term care (MOHLTC). The opinions, results and conclusions reported in this paper are those of the authors and are independent from the funding sources. No endorsement by ICES or the Ontario MOHLTC is intended or should be inferred. Parts of this material are based on data and information compiled and provided by the Canadian Institute for Health Information (CIHI). The opinions, results and conclusions reported in this paper are those of the authors and are independent from the funding sources and CIHI. Dr. Cheung receives funding from the Roy and Marjorie Linden Fund and the Joan Fisher and James Rowland Fund.

\section{Compliance with Ethical Standards:}

Conflict of Interest: WKS, $C D, R C$, and MCC had no competing financial interests.

\section{REFERENCES}

1. Silverstein WK, Lin Y, Dharma CD, et al. Prevalence of inappropriateness of parenteral vitamin $\mathrm{B}_{12}$ administration in Ontario, Canada. JAMA Intern Med. 2019;179:1434-6

2. Green R, Allen LH, Bjørke-Monsen AL, et al. Vitamin B12 deficiency. Nat Rev Dis Primers. 2017;3:17040.

3. Dhalla IA, Anderson GM, Mamdani MM, et al. Inappropriate prescribing before and after nursing home admission. J Amer Geriatr Soc. 2002;50:995-1000.

4. Berthold HK, Gouni-Berthold I, Bestehorn KP, Böhm M, Krone W. Physician gender is associated with the quality of type 2 diabetes care. J Intern Med. 2008;264:340-350.

5. Graham ID, Jette N, Tetroe J, Robinson N, Milne S, Mitchell SL. Oral cobalamin remains medicine's best kept secret. Arch Gerontol Geriatr. 2007:44:49-59.

6. Silverstein WK, Lin Y, Cheung MC. Vitamin B12 therapy in older adults and misconception of its inappropriateness - In Reply. JAMA Intern Med. 2019;179:1606-1607.

Publisher's Note: Springer Nature remains neutral with regard to jurisdictional claims in published maps and institutional affiliations. 